\title{
Frequency of Hypocalcemic Fits in Children 2 Months to 2 Years of Age, Presenting with the First Episode of Afebrile Seizures at Hospital Settings in Urban Pakistan: A Cross-Sectional Study
}

\author{
Waseem Rahman, Heeramani Lohana*, Sarwat Urooj, Sherza Ahmed, Abdul Moeed, \\ Khadija Humayun
}

Aga Khan Maternal and Child Care Centre, Hyderabad, Pakistan

Email: `heeramani.lohana@aku.edu

How to cite this paper: Rahman, W. Lohana, H., Urooj, S., Ahmed, S., Moeed, A. and Humayun, K. (2020) Frequency of Hypocalcemic Fits in Children 2 Months to 2 Years of Age, Presenting with the First Episode of Afebrile Seizures at Hospital Settings in Urban Pakistan: A Cross-Sectional Study. Open Journal of Pediatrics, 10, 411-422. https://doi.org/10.4236/ojped.2020.103042

Received: June 5, 2020

Accepted: August 11, 2020

Published: August 14, 2020

Copyright $\odot 2020$ by author(s) and Scientific Research Publishing Inc. This work is licensed under the Creative Commons Attribution International License (CC BY 4.0).

http://creativecommons.org/licenses/by/4.0/ (c) (i) Open Access

\begin{abstract}
Introduction: Seizures are common in the pediatric age group, occurring approximately $10 \%$ of children. Hypocalcemia is one of the most common metabolic causes of afebrile seizures. The objective of the study was to determine the frequency of hypocalcemic fits in children presenting with the first episode of afebrile seizures from 2 months to 2 years of age. Methods: The study was conducted at the Aga Khan hospital Karachi and its three secondary hospitals including the following sites of Kharadar, Hyderabad, and garden. It was a cross-sectional study. The duration of the study was of 6 months from 18th July 2017 to 18th Jan. 2018. All patients who fulfill the inclusion criteria and visited the Pediatric medicine Department of Aga Khan Hospital, Karachi, and its secondary hospitals were included in the study after ethical approval and informed and written consent. A brief history was taken, clinical examination was done and serum calcium level was sent to the institutional laboratory to reach the outcome i.e. hypocalcemic fits. Result: A total of 85 children presenting with the first episode of afebrile seizures were included. Total of 45 patients (52.98\%) were males \& 40 patients 2 (47.1\%) were females with the mean age were $10.5824 \pm 6.84907$ months. The hypocalcemic fits were seen in 21 children (24.7\%). Discussion: Hypocalcemia is a common cause of afebrile fits in children. Inadequate sun exposure, early age, male gender, low weight, and illiteracy are major risk factors for hypocalcemia.
\end{abstract}




\section{Keywords}

Hypocalcemia, Seizure, Convulsions, Risk Factors, Children

\section{Introduction}

In children, hypocalcemia is defined as a total serum calcium concentration of less than $2.1 \mathrm{mmol} / \mathrm{L}(8.5 \mathrm{mg} / \mathrm{dL})$ [1]. Seizures are common in the pediatric age group and occur in approximately $10 \%$ of children [2]. Amongst the various etiologies; hypocalcemia is a major biochemical cause of seizures in infancy in developing countries [3]. It constitutes $25.6 \%$ of afebrile seizures in children [4]. In a local study, hypocalcemia accounted for $68.3 \%$ of afebrile seizures [5].

The presence of seizure does not constitute a diagnosis but it is a symptom of an underlying central nervous system disorder due to systemic or biochemical disturbances [6]. Hypocalcemia in children may manifest as tetany, seizures, muscle cramps, and paresthesias [7]. The central nervous system irritability from hypocalcemia can cause anticonvulsant-resistant seizures. Such seizures often are brief, lasting a few seconds or minutes, but may recur frequently. Initially, there may be no postictal phase. Rarely, it may present with stridor or cyanosis from laryngospasm. Arrhythmias are even rarer. Electrocardiography may reveal a prolonged QTc interval. Most patients who have mild hypocalcemia are asymptomatic [8].

Hypocalcemia is associated with poor outcomes as measured by either survival or length of intensive care stay [9]. Infants fed with buffalo or cow's milk or formula containing a high amount of phosphate are also low in calcium because phosphate decreases the absorption of calcium. Balasubramanian et al. [10] in India identified indoor confinement during the day, living in urban areas with tall buildings, and the use of sunscreen as major risk factors for hypocalcemia. In another study, fresh unfortified milk, inadequate exposure to sunlight, lower maternal educational status, and large family size as risk factors for hypocalcemia.

Acute hypocalcemia is an emergency that requires prompt attention, and patients with symptomatic hypocalcemia should be treated immediately because of the highly associated morbidity and mortality. Treatment with intravenous calcium is the most appropriate therapy. Hypocalcemic seizures should be treated with calcium replacement, while AEDs are typically not needed. AEDs may abolish both overt and latent tetany, whereas hypocalcemic seizures may remain refractory [11]. There is a shortage of data in the pediatric population regarding the frequency of hypocalcemia in afebrile seizures. This study will help us to find out the frequency of hypocalcaemic fits to look into the consideration of empiric $\mathrm{I} / \mathrm{V}$ calcium in afebrile fits patients that did not respond to anticonvulsant drug. Because in developing countries like Pakistan; it is worthwhile to give empiric $\mathrm{I} / \mathrm{V}$ calcium in non-responsive afebrile fits. The benefit to the patient will be the 
prevention of the harmful effects of hypocalcemic seizures. These results can be used in planning and priority setting.

\subsection{Objectives}

To determine the frequency of hypocalcaemic fits in children presenting with the first episode of afebrile seizures; from 2 months to 2 years of age.

\subsection{Operational Definitions}

1) Hypocalcemia: Serum calcium level $<8.5 \mathrm{mg} / \mathrm{dl}$ in children.

2) Fever: temperature $>100.4 \mathrm{~F}$ at the time of fits.

3) Afebrile seizures: Presence of fits in the absence of fever.

4) Fits (convulsions): abnormal involuntary jerky movements of any part of the body.

5) Hypocalcemic fits: fits which were due to low levels of calcium $(<8.5 \mathrm{mg} / \mathrm{dl})$ in blood.

6) Malnourishment (any child with weight for height/length above-2SD on WHO standardized growth chart was classified as malnourished).

7) Sun Exposure (sun exposure of less than $30 \mathrm{~min} /$ week was considered as inadequate).

\section{Methods}

\subsection{Study Design}

Cross-sectional study.

\subsection{Setting}

The Aga Khan Hospital Karachi and its secondary hospitals including the following sites:

1) Kharadar.

2) Hyderabad.

3) Garden.

\subsection{Duration of Study}

Was 6 months from 18th July 2017 to 18th Jan. 2018.

\subsection{Sample Size}

Sample size calculated using the WHO calculator taking the margin of error as $10 \%$, confidence interval as $95 \%$, and taking frequency of hypocalcemia (in afebrile fits) $68.3 \%$ (based on the previous study) [5], sample size came out to be 85 .

\subsection{Sampling Technique}

Non-probability consecutive sampling.

Inclusion criteria:

Children from 2 months to 2 years of age having afebrile fits. 


\section{Exclusion criteria}

Children having the previous history of fits/epilepsy.

Children with fever at the time of fits.

\section{Ethical consideration}

This study was post-graduation thesis project of Dr. Waseem and the thesis was approved by the College of Physicians and Surgeons, Pakistan. The study was also approved by Aga Khan University's Ethical review committee in 2017.

\subsection{Data Collection Procedure}

All children of the specified age group, who present with fits and no fever at the designated study sites, were enrolled in the study as per inclusion and exclusion criteria. All the data was recorded on a structured proforma; after reviewing the concerned medical records. Serum calcium levels were determined from the laboratory. Age, gender, and other relevant information were obtained from the caregiver. The patient was observed for fits and the duration of fits was documented. For confidentiality, all study participants were allotted a unique ID (other than hospital registration number) for study enrolment. Principle investigator himself was collecting the data. The study protocol was approved by the Ethical Review Board of Aga khan university hospital.

Informed consent was taken from the caregiver of the participant child. The caregiver was explained that participation in the study was voluntary, and no monetary compensation was given for the cost of an investigation.

\subsection{Data Analysis Procedure}

All the collected data were entered and analyzed in SPSS software version 19. Frequency and percentages were computed for categorical variables like gender, feeding pattern, sunlight exposure, nutritional status mother education, socioeconomic status, and hypocalcemic fits. Mean and the standard deviation was calculated for quantitative variables like age, weight, and height. Effect modifiers like age, gender, weight, feeding pattern, sunlight exposure, nutritional status, mother education, and socioeconomic status were controlled through stratification. Post-stratification chi-square test was applied by taking p-value $<0.05$ as significant.

\section{Result}

A total of 85 children presenting with the first episode of afebrile seizures were selected to conduct this study. The mean age was $10.5824 \pm 6.84907$ months. The distribution of age is presented in Figure 1. Forty-five patients $(52.98 \%)$ were males \& forty patients (47.1\%) were females. The mean weight was $6.67 \pm 2.482$ $\mathrm{kg}$. The mean height was $69.74 \pm 11.678 \mathrm{cms}$. The mean serum calcium level was $8.76 \pm 1.7704 \mathrm{mg} / \mathrm{dl}$. The distribution of serum calcium levels is presented in Figure 2. The descriptive statistics of weight, height, and serum calcium level are presented in Table 1. 


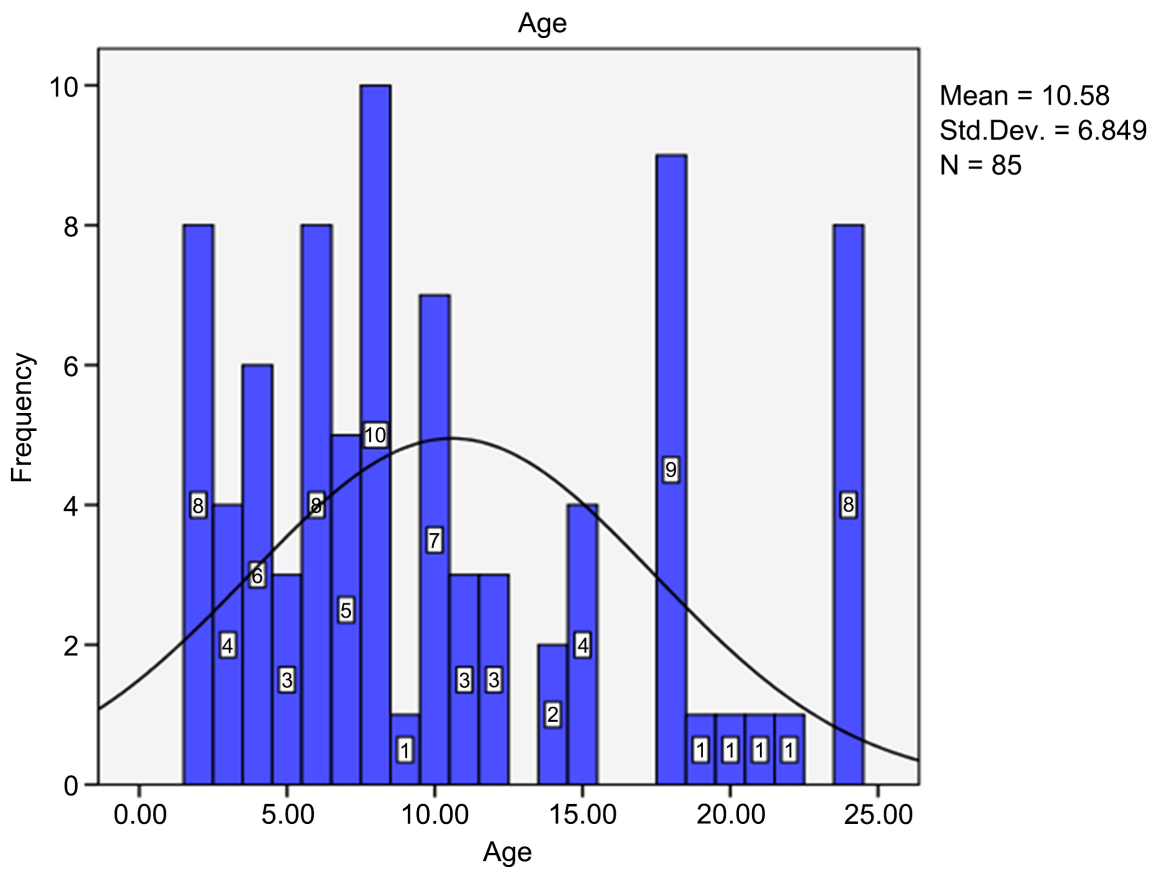

Figure 1. Frequency distribution of age.

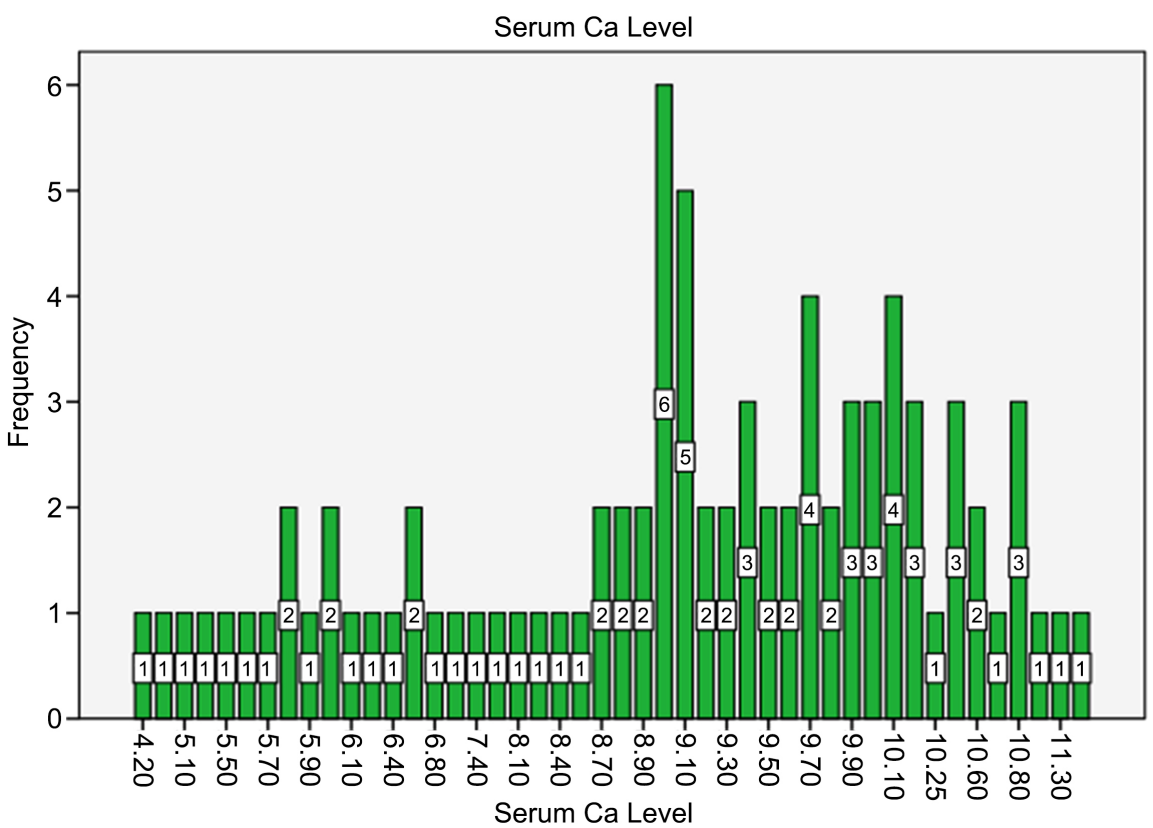

Figure 2. Frequency distribution of serum calcium level.

Table 1. Descriptive statistics of age, weight \& serum calcium level.

\begin{tabular}{cccc}
\hline Statistics & Weight $(\mathrm{kg})$ & Height $(\mathrm{cm})$ & Serum calcium level \\
\hline Minimum & 3 & 45 & 4.2 \\
Maximum & 16 & 96 & 12.5 \\
Mean \& Std. Deviation & $6.67 \pm 2.482$ & $69.74 \pm 11.678$ & $8.76 \pm 1.7704$ \\
Median & 7.50 & 68.50 & 9.20 \\
\hline
\end{tabular}


In our study, sun exposure was adequate in 57 patients $(67.1 \%)$ and inadequate in $28(32.9 \%)$. As shown in Table 2, 41 mothers (48.2\%) were literate while $44(51.8 \%)$ were illiterate. In socioeconomic status, 23 patients $(27.1 \%)$ had income of $<10,000$ rupees/month, 52 (61.2\%) had between 10,000 to $25,000 \mathrm{ru}$ pees/month and 10 (11.8\%) had above 25,000 rupees/month (Table 2). 28 children (32.9\%) were malnourished and 57 (67.1\%) were well-nourished (Table $3)$. The feeding pattern was breast milk in 40 children (47.05\%), formula milk in $39(45.88 \%)$, and fresh milk in $6(7.05 \%)$, as shown in Table 3. The outcome i.e. hypocalcemic fits were seen in 21 children $(24.7 \%)$ presenting with the first episode of afebrile seizures, as shown in Table 4.

The frequencies of age groups, gender, weight, height, feeding pattern, sunlight exposure, nutritional status, mother education, socioeconomic status was calculated according to hypocalcemic fits and are presented in Table 4, Table 5, and Table 6 respectively.

The stratification according to age groups, gender, weight, height, feeding pattern, sunlight exposure, nutritional status, mother education, socioeconomic status was done to observe the effect of these modifiers on hypocalcemic fits.

Hypocalcemia fits were common in children of the age group of $2-12$ months $(68 \%)$, predominant in male gender $(53 \%)$, and children with the low weight falling in 3 - $9 \mathrm{Kg}(75 \%)$ and also more common in children with inadequate sunlight exposure and illiterate mothers.

Table 2. Frequency distribution of sun exposure, mother's education, socioeconomic status.

\begin{tabular}{ccc}
\hline SUN exposure & $\begin{array}{c}\text { Frequency } \\
\mathrm{N}=(85)\end{array}$ & $\begin{array}{c}\text { Percentage } \\
(\%)\end{array}$ \\
Adequate & 57 & $67.1 \%$ \\
Inadequate & 28 & $32.9 \%$ \\
Total & 85 & $100 \%$ \\
Mother's Education & & \\
Literate & 41 & $48.2 \%$ \\
Illitrate & 44 & $51.8 \%$ \\
Total & 85 & $100 \%$ \\
Socioeconomic Status & & \\
$<10,000$ Rupees/Month & 23 & $100 \%$ \\
Between 10,000 to 25,000 & & \\
Rupees/Month & 52 & $61.2 \%$ \\
Tobo 25,000 Rupees/Month & 10 & $11.8 \%$ \\
Above & 85 &
\end{tabular}


Table 3. Frequency distribution of nutritional status, feeding pattern, hypocalcemic fits.

\begin{tabular}{ccc}
\hline Nutritional Status & $\begin{array}{c}\text { Frequency } \\
\mathrm{N}=(85)\end{array}$ & Percentage (\%) \\
\hline Malnourished & 28 & $32.9 \%$ \\
Well Nourished & 57 & $67.1 \%$ \\
Total & 85 & $100 \%$ \\
Feeding Pattern & & \\
Breast milk & 40 & $47.05 \%$ \\
Formula milk & 39 & $45.88 \%$ \\
Fresh milk & 6 & $7.05 \%$ \\
Total & 85 & $100 \%$ \\
Hypocalcemic Fits & & $24.7 \%$ \\
Yes & 21 & $75.3 \%$ \\
No & 64 & $100 \%$ \\
Total & 85 & \\
\hline
\end{tabular}

Table 4. Hypocalcemia fits according to age, gender, weight, height.

\begin{tabular}{|c|c|c|c|c|}
\hline \multirow{2}{*}{ Age months } & \multicolumn{2}{|c|}{ Hypocalcemia fits } & \multirow{2}{*}{ Total } & \multirow{2}{*}{ P-Value } \\
\hline & Yes & No & & \\
\hline $2-12$ months & $19(22.35 \%)$ & $39(45.88 \%)$ & $58(68.23 \%)$ & \\
\hline $13-24$ months & $2(2.35 \%)$ & $25(29.41 \%)$ & $27(31.76 \%)$ & 0.084 \\
\hline Total & $21(24.70 \%)$ & $64(75.29 \%)$ & $85(100 \%)$ & \\
\hline \multirow{2}{*}{ Gender } & \multicolumn{2}{|c|}{ Hypocalcemia fits } & \multirow{2}{*}{ Total } & \multirow{2}{*}{ P-Value } \\
\hline & Yes & No & & \\
\hline Male & $14(16.47 \%)$ & $31(36.47 \%)$ & $45(52.94 \%)$ & \\
\hline Female & $7(8.23 \%)$ & $33(38.82 \%)$ & $40(47.05 \%)$ & 0.146 \\
\hline Total & $21(24.70 \%)$ & $64(75.29 \%)$ & $85(100 \%)$ & \\
\hline \multirow{2}{*}{ Weight } & \multicolumn{2}{|c|}{ Hypocalcemia fits } & \multirow{2}{*}{ Total } & \multirow{2}{*}{ P-Value } \\
\hline & Yes & No & & \\
\hline $3-9 \mathrm{~kg}$ & $20(23.52 \%)$ & $44(51.7 \%)$ & $64(75.29 \%)$ & \\
\hline $10-16 \mathrm{~kg}$ & $1(1.17 \%)$ & $20(23.52 \%)$ & $21(24.70 \%)$ & 0.511 \\
\hline Total & $21(24.70 \%)$ & $64(75.29 \%)$ & $85(100 \%)$ & \\
\hline \multirow{2}{*}{ Height } & \multicolumn{2}{|c|}{ Hypocalcemia fits } & \multirow{2}{*}{ Total } & \multirow{2}{*}{ P-Value } \\
\hline & Yes & No & & \\
\hline $45-70 \mathrm{cms}$ & $17(20 \%)$ & $30(35.29 \%)$ & $47(55.29 \%)$ & \\
\hline $71-96 \mathrm{cms}$ & $4(4.70 \%)$ & $34(40 \%)$ & $34(40 \%)$ & 0.522 \\
\hline Total & $21(24.70 \%)$ & $64(75.29 \%)$ & $85(100 \%)$ & \\
\hline
\end{tabular}

Chi Square test was applied. P-value $\leq 0.05$ considered as significant. 
Table 5. Hypocalcemia fits according to sun exposure, mother's education, nutritional status \& socioeconomic status $(\mathrm{n}=85)$.

\begin{tabular}{|c|c|c|c|c|}
\hline \multirow{2}{*}{ Sun exposure } & \multicolumn{2}{|c|}{ Hypocalcemia fits } & \multirow{2}{*}{ Total } & \multirow{2}{*}{ P-Valu } \\
\hline & Yes & No & & \\
\hline Adequate & $9(10.58 \%)$ & $48(56.47 \%)$ & $57(67.05 \%)$ & \\
\hline Inadequate & $12(14.11 \%)$ & $16(18.82 \%)$ & $28(32.94 \%)$ & 0.011 \\
\hline Total & $21(24.70 \%)$ & $64(75.29 \%)$ & $85(100 \%)$ & \\
\hline \multirow{2}{*}{ Mother's Education } & \multicolumn{2}{|c|}{ Hypocalcemia fits } & \multirow{2}{*}{ Total } & \multirow{2}{*}{ P-Value } \\
\hline & Yes & No & & \\
\hline Literate & $7(8.23 \%)$ & $34(40 \%)$ & $41(48.23 \%)$ & \\
\hline Illitrate & $14(16.47 \%)$ & $30(35.29 \%)$ & $44(51.76 \%)$ & 0.115 \\
\hline Total & $21(24.70 \%)$ & $64(75.29 \%)$ & $85(100 \%)$ & \\
\hline \multirow{2}{*}{ Nutritional Status } & \multicolumn{2}{|c|}{ Hypocalcemia fits } & \multirow{2}{*}{ Total } & \multirow{2}{*}{ P-Value } \\
\hline & Yes & No & & \\
\hline Malnourished & $8(9.41 \%)$ & $20(23.52 \%)$ & $28(32.94 \%)$ & \\
\hline Well Nourished & $13(15.29 \%)$ & $44(51.76 \%)$ & $57(67.05 \%)$ & 0.566 \\
\hline Total & $21(24.70 \%)$ & $64(75.29 \%)$ & $85(100 \%)$ & \\
\hline \multirow{2}{*}{ Socioeconomic Status } & \multicolumn{2}{|c|}{ Hypocalcemia fits } & \multirow{2}{*}{ Total } & \multirow{2}{*}{ P-Valu } \\
\hline & Yes & No & & \\
\hline$<10,000$ Rupees/Month & $9(10.58 \%)$ & $14(16.47 \%)$ & $23(27.05 \%)$ & \multirow{4}{*}{0.052} \\
\hline $\begin{array}{c}\text { Between } 10,000 \text { to } \\
25,000 \text { Rupees/Month }\end{array}$ & $12(14.11 \%)$ & $40(47.05 \%)$ & $52(61.17 \%)$ & \\
\hline $\begin{array}{l}\text { Above } 25,000 \\
\text { Rupees/Month }\end{array}$ & $0(\%)$ & $10(11.76 \%)$ & $10(11.76 \%)$ & \\
\hline Total & $21(24.70 \%)$ & $64(75.29 \%)$ & $85(100 \%)$ & \\
\hline
\end{tabular}

Chi Square test was applied. P-value $\leq 0.05$ considered as significant.

Table 6. Hypocalcemia fits according to feeding pattern $(n=85)$.

\begin{tabular}{ccccc}
\hline \multirow{2}{*}{ Feeding Pattern } & \multicolumn{2}{c}{ Hypocalcemia fits } & Total & P-Value \\
\cline { 2 - 3 } & Yes & No & & \\
\hline Breast Milk & $11(12.94 \%)$ & $29(34.11 \%)$ & $40(47.05 \%)$ & \\
Formula Milk & $2(2.35 \%)$ & $4(4.70 \%)$ & $6(7.05 \%)$ & \multirow{2}{*}{0.356} \\
Fresh milk & $8(9.41 \%)$ & $31(36.47 \%)$ & $39(45.88 \%)$ & \\
Total & $21(24.70 \%)$ & $64(75.29 \%)$ & $85(100 \%)$ & \\
\hline
\end{tabular}

Chi Square test was applied. P-value $\leq 0.05$ considered as significant. 


\section{Discussion}

Seizures are one of the most common neurological disorders in children. The first episode of epileptic seizure is always an anxiety-causing event for parents and it is the health professional's duty to know the best approach and recommendations to use in each case. Seizures are common in the pediatric age group and one of the most common biochemical abnormalities causing seizures is hypocalcemia [12]. Hypocalcemia is emerging as a very common problem perhaps due to a lack of awareness of the morbid consequences [13].

In our study hypocalcemic fits were seen in 21 children (24.7\%) presenting with the first episode of afebrile seizures, as compared to Khan et al. [5] study, $41(68 \%)$ cases were hypocalcemic among the total study population of 60 . In our study, the mean age was $10.5824 \pm 6.84907$ years as compare to Khan et al. [5] study the mean age at the time of admission was $7.5 \pm 1.34$ months. The majority of children (51.2\%) were below 6 months. This is also consistent with results by Binmohana et al., [12] and Humayun et al. [13] but is in contrast with Abanamy et al. [13] showing 39.2\% patients less than 6 months of age. The present study noted slight male predominance $52.98 \%$ comparable with Khan et al. study showed (56\%) and with Binmohana MA et al. [12] but Sharma et al. [14] found no gender difference. Inadequate exposure to sunlight is an important factor associated with the development of vitamin D-deficient rickets which in turn is a common cause in $73 \%$ of hypocalcemia in children [13] [15]. Our study highlighted this fact and the results showed (32.9\%) children had inadequate sunlight exposure in contrast to Khan et al. [5] study showed the high number of children (68.3\%) had poor exposure to sunlight. Balasubramanian et al. [10] in India identified indoor confinement during the day, living in urban areas with tall buildings, and the use of sunscreen as major risk factors for hypocalcemia. In another study, fresh unfortified milk, inadequate exposure to sunlight, lower maternal educational status, and large family size as risk factors for hypocalcemia, and these results are comparable with other studies [5] [14]. In the present study, the feeding pattern was breast milk in 40 children (47.05\%), formula milk in $39(45.88 \%)$ \& fresh milk in 6 (7.05\%), as compared to Khan et al. [5] study, $63.4 \%$ children received unfortified fresh milk, $34 \%$ breast milk and $2.4 \%$ formula milk. These results are also comparable with observations made by Temashek et al. [16]. Hypocalcemia is associated with poor outcomes as measured by either survival or length of intensive care stay [17]. Infants fed with buffalo or cow's milk or formula containing a high amount of phosphate are also low in calcium because phosphate decreases the absorption of calcium. In our study 28 children (32.9\%) were malnourished and 57 (67.1\%) were well nourished. However, Hatun et al. [18] observed that $83 \%$ infant who had vitamin D deficiency were exclusive breastfeed without supplemental vitamin D. Khan et al. [5] study showed $36.5 \%$ children with inadequate weaning and is comparable with results of Carvelt NF et al. [19] and Younas M et al. [20]. 32.9\% of our study population was malnourished as compared to Khan et al. [9] study showed 
seventy-two percent of the study population had malnutrition according to Gomez classification which is comparable to a study by Khattak et al. [21] The mean weight in the present study was $6.67 \pm 2.482 \mathrm{~kg}$ and the mean height was $69.74 \pm 11.678 \mathrm{cms}$. One previous study showed that $46 \%$ were low birth weight while $17 \%$ were preterm [10], the incidence of hypocalcemia is inversely proportional to gestational age and birth weight [21]. Recently, a study by Raazia Nawaz et al showed hypocalcemia prevalence of $51 \%$ in premature and low birth weight babies [22]. Hypocalcemia can be present with a wide variety of symptoms, the most important of which is seizures. In $90 \%$ of cases, seizure type was noted generalized tonic-clonic which was comparable with Sharma et al. [23]. Elevated alkaline phosphatase $>1000 \mathrm{1U} / \mathrm{L}$ was observed in $53.3 \%$ patient which is consistent with other studies [24]. This study showed that $76 \%$ of patients had radiological evidence of rickets in the form of cupping and fraying and is comparable with the results of New-ham et al. [25].

The limitation of this study was that we did not correlate hypocalcemia with magnesium levels.

\section{Conclusion}

Hypocalcemia is a common cause of afebrile fits in children. Inadequate sun exposure, early age, male gender, low weight, and illiteracy are major risk factors for hypocalcemia

\section{Acknowledgements}

We would like to acknowledge mothers of enrolled children for providing us time and data for this study. We would also like to thank all our nursing staff in conducting this study under stressful conditions.

\section{Ethics Approval and Consent to Participate}

Aga Khan University Hospital ethical review committee approved the study in December 2017 with ERC number 5123-Ped-ERC-17.

\section{Funding}

The study was self-funded by Dr. Waseem ur Rahman.

\section{Authors' Contributions}

WR, SA and HL contributed to drafting the article. WR conducted the research at hospitals. SU and AM conducted the research. WR and HL managed and analyzed data. $\mathrm{KH}$ designed and supervised the study. All authors approved the final version of the article for submission.

\section{Competing Interests}

The authors declare that they have no competing interests. 


\section{References}

[1] Malhotra, Y. and Bowden, S.A. (2019) Pediatric Hypocalcemia. https://emedicine.medscape.com/article/921844-overview

[2] Kliegman, R., Behrman, R., Jenson, H. and Stanton, B. (2007) Nelson Textbook of Pediatrics. 18th Edition, Saunders, Philadelphia.

[3] Ahmed, I., Atiq, M., Iqbal, J., Khurshid, M. and Whittaker, P. (1995) Vitamin D Deficiency Rickets in Breast-Fed Infants Presenting with Hypocalcaemic Seizures. Acta Paediatrica, 84, 941-942. https://doi.org/10.1111/j.1651-2227.1995.tb13798.x

[4] Balasubramanian, S., Shivbalan, S. and Kumar, P.S. (2006) Hypocalcemia Due to Vitamin D Deficiency in Exclusively Breastfed Infants. Indian Pediatrics, 43, 247-251.

[5] Khan, M.A., Iqbal, S.M.J., Afzal, M.F. and Sultan, M.A. (2011) Frequency of Hypocalcemic Fits in Children Presenting with Afebrile Seizures and Risk Factors for Hypocalcemia. A Descriptive Study. Annals of King Edward Medical University, 17, 31 .

[6] Sood, A., Grover, N. and Sharma, R. (2003) Biochemical Abnormalities in Neonatal Seizures. Indian Journal of Pediatrics, 70, 221-224.

https://doi.org/10.1007/BF02725588

[7] Singhi, S.C., Singh, J. and Prasad, R. (2003) Hypocalcaemia in a Paediatric Intensive Care Unit. Journal of Tropical Pediatrics, 49, 298-302. https://doi.org/10.1093/tropej/49.5.298

[8] Zhou, P. and Markowitz, M. (2009) Hypocalcemia in Infants and Children. Pediatrics in Review, 30, 190-192. https://doi.org/10.1542/pir.30-5-190

[9] Khan, H.I., Abdullah, A., Kazi, M.Y. and Afzal, M.F. (2006) Hypocalcemia and Nutritional Rickets in Children: Common Etiological Factors. Annals of King Edward Medical University, 12, 29-32. https://doi.org/10.21649/akemu.v12i1.819

[10] Balasubramanian, S. and Ganesh, R. (2008) Vitamin D Deficiency in Exclusively Breast-Fed Infants. Indian Journal of Medical Research, 127, 250-255.

[11] Nardone, R., Brigo, F. and Trinka, E. (2016) Acute Symptomatic Seizures Caused by Electrolyte Disturbances. Journal of Clinical Neurology, 12, 21-33. https://doi.org/10.3988/jen.2016.12.1.21

[12] BinMohanna, M.A, Raja'a, Y.A. and Saif, G.A. (2005) Prevalence of Hypocalcemia in Children Examined for Serum Calcium in Sana'a, Yemen. Saudi Medical Journal, 26, 457-459.

[13] Abanamy, A., Salman, H., Cheriyan, M., Shuja, M. and Siddrani, S. (1991) Vitamin D Deficiency Rickets in Riyadh. Annals of Saudi Medicine, 11, 35-39. https://doi.org/10.5144/0256-4947.1991.35

[14] Anushma Sharma, D.N.V. (2003) Rickets in Walled City of Delhi. https://www.indianpediatrics.net/sep2003/sep-908-909.htm

[15] Elsary, A.Y., Elgameel, A.A., Mohammed, W.S., Zaki, O.M. and Taha, S.A. (2018) Neonatal Hypocalcemia and Its Relation to Vitamin D and Calcium Supplementation. Saudi Medical Journal, 39, 247-253.

[16] Tomashek, K.M., Nesby, S., Scanlon, K.S., Cogswell, M.E., Powell, K.E., Parashar, U.D., et al. (2001) Nutritional Rickets in Georgia. Pediatrics, 107, e45. https://doi.org/10.1542/peds.107.4.e45

[17] Erfan, A.A., Nafie, O.A., Neyaz, A.A. and Hassanein, M.A. (1997) Vitamin D Deficiency Rickets in Maternity and Children's Hospital, Makkah, Saudi Arabia. Annals of Saudi Medicine, 17, 371-373. https://doi.org/10.5144/0256-4947.1997.371 
[18] Hatun, S., Ozkan, B., Orbak, Z., Doneray, H., Cizmecioglu, F., Toprak, D., et al. (2005) Vitamin D Deficiency in Early Infancy. Journal of Nutrition, 135, 279-282. https://doi.org/10.1093/jn/135.2.279

[19] Carvalho, N.F., Kenney, R.D., Carrington, P.H. and Hall, D.E. (2001) Severe Nutritional Deficiencies in Toddlers Resulting from Health Food Milk Alternatives. Pediatrics, 107, e46. https://doi.org/10.1542/peds.107.4.e46

[20] Yonas, M.R.F. (2003) A Cross-Sectional Study on Epidemiology of Rickets in Pakistani Children. JMS, 11, 26-32.

[21] Khattak, A.A., Rehman, G., Shah, F.U. and Khan, M.K. (2004) Study of Ricket in Admitted Patient at Lady Reading Hospital, Peshawar. JPMI, 18, 52-58.

[22] Nawaz, R., Hussain, S., Khushdil, A., Ghafoor, T., Akram, S. and Tanveer, S. (2020) Hypocalcemia among Preterm and Very Low Birth Weight Neonates in a Tertiary Care Neonatal Unit. Pakistan Armed Forces Medical Journal, 70, 195-200.

[23] Sharma, J., Bajpai, A., Kabra, M. and Menon, P.S. (2002) Hypocalcemia Clinical, Biochemical, Radiological Profile and Follow-Up in a Tertiary Hospital in India. Indian Pediatrics, 39, 276-282.

[24] El Hag, A.I. and Karrar, Z.A. (1995) Nutritional Vitamin D Deficiency Rickets in Sudanese Children. Annals of Tropical Paediatrics, 15, 69-76. https://doi.org/10.1080/02724936.1995.11747751

[25] Ladhani, S., Srinivasan, L., Buchanan, C. and Allgrove, J. (2004) Presentation of Vitamin D Deficiency. Archives of Disease in Childhood, 89, 781-784.

https://doi.org/10.1136/adc.2003.031385 